\title{
Association between dyspeptic symptoms and endoscopic findings based on the Kyoto classification of gastritis in Japanese male
}

\author{
Kouji Takahashi, ${ }^{1, *}$ Mitsushige Sugimoto, ${ }^{1}$ Yusuke Kawai, ${ }^{1}$ Mariko Hamada, ${ }^{1}$ Eri Iwata, ${ }^{1}$ Ryota Niikura, ${ }^{1}$ \\ Naoyoshi Nagata, ${ }^{1}$ Masakatsu Fukuzawa, ${ }^{2}$ Takao Itoi, ${ }^{2}$ Tetsuo Ohtsubo, ${ }^{3}$ and Takashi Kawai ${ }^{1}$ \\ 1Department of Gastroenterological Endoscopy and ${ }^{2}$ Department of Gastroenterology, Tokyo Medical University Hospital, \\ 6-7-1, Nishishinkuku, Shinjuku-ku, Tokyo 160-0023, Japan \\ ${ }^{3}$ Fuyo Clinic, 5-14-5, Shinjuku, Shinjuku-ku, Tokyo 160-0022, Japan
}

(Received 14 June, 2021; Accepted 7 August, 2021)

\begin{abstract}
The Kyoto gastritis classification is used to categorize the endoscopic characteristics of Helicobacter pylori infectionassociated gastritis. We aimed to clarify the association among endoscopic findings and abdominal dyspeptic symptoms in Japanese male. We administered a questionnaire to 418 subjects who underwent endoscopy as part of a health check-up from August 2003 to April 2004 to investigate the association among endoscopic findings of the Kyoto classification and the presence of dyspeptic symptoms. Logistic regression analyses were performed to evaluate risk based on dyspeptic symptoms. Among 418 health check-up subjects, $21.3 \%$ (89/418) reported dyspeptic symptoms in the questionnaire. The incidence of fundic gland polyp among patients with dyspeptic symptoms was $12.4 \%$ (11/89), which was significantly higher than that among nonsymptomatic subjects $(4.3 \%, 14 / 329, p=0.004)$. Logistic regression analyses showed that fundic gland polyp was a risk factor for dyspeptic symptoms [odds ratio (OR): $3.413,95 \%$ confidence interval (Cl): 1.430-8.142], while short-segment Barrett's esophagus and male sex were protective factors (OR: $0.569,95 \%$ Cl: $0.349-0.928$ and OR: $0.333,95 \% \mathrm{Cl}: 0.117-0.948$, respectively). In conclusion, Endoscopic findings of fundic gland polyp may be associated with dyspeptic symptoms, which in turn may be a useful marker of gastric condition.
\end{abstract}

Key Words: abdominal symptom, gastritis, Kyoto classification, Helicobacter pylori, questionnaires

I n 1994, the World Health Organization's International Agency for Research on Cancer categorized Helicobacter pylori (H. pylori) as a group I carcinogenic factor of gastric cancer. $^{(1,2)}$ Over the following 30 years, much basic and clinical research focused on clarifying the association between $H$. pylori and gastric cancer. This has led to a global decline in the incidence of gastric cancer over the past half-century, especially in Western countries, due to a decrease in the H. pylori infection rate and increase in eradication therapy. ${ }^{(3)}$ It is important to evaluate the relative impact of environmental, genetic and bacterial factors, and endoscopic findings on gastric cancer risk. ${ }^{(4,5)}$ Pathological reporting systems, including the Houstonupdated Sydney system and the operative link on gastritis assessment system, and endoscopic reporting systems, such as the Kyoto gastritis classification, are increasingly being used to identify patients at high risk for gastric cancer. ${ }^{(5-8)}$ The Kyoto classification, which grades endoscopically-visible risk factors, first divides patients into three groups (H. pylori-negative, -positive, and previously infected) and, second, categorizes gastric cancer risk based on the scores for five features of gastritis (atrophy, intestinal metaplasia, enlarged folds, nodularity, and diffuse redness). ${ }^{(5)}$ Intestinal metaplasia and atrophy features of the Kyoto classification have been proven to be clinically useful for identifying patients at elevated risk for gastric cancer, irrespective of $H$. pylori infection. ${ }^{(5,9,10)}$ It is reported that Kyoto classification of gastritis is useful for diagnosis of $H$. pylori infection in subjects with a high-negative titer of anti- $H$. pylori antibody. ${ }^{(1)}$

Functional dyspepsia (FD) is defined as "pain or upper abdominal discomfort, chronic or recurrent of at least 12 weeks duration, not necessarily consecutive, within the preceding 12 months" in the Rome IV criteria. Around $10 \%$ of the general population in the USA (12\%), Canada (8\%) and UK (8\%) fulfill the Rome IV criteria. ${ }^{(12)}$ In Japan, the prevalence of patients with dyspeptic symptoms is increasing. While the pathogenesis of FD is multifactorial (i.e., abnormal gastrointestinal motility, visceral hypersensitivity, psychosocial factors, and disorders of the autonomic and central nervous system), ${ }^{(13,14)}$ the condition of the gastric mucosa in relation to $H$. pylori is considered a key factor. Guidelines established by the American College of Gastroenterology therefore strongly recommend $H$. pylori eradication for $H$. pylori-positive FD patients. ${ }^{(15)}$ Similarly, the Japanese guidelines for FD recommend $H$. pylori eradication for $H$. pyloripositive dyspepsia patients, and those who are symptom-free 612 months after eradication are considered " $H$. pylori-associated FD" cases. ${ }^{(16)}$ However, the association between dyspeptic symptoms and endoscopic severity of gastritis and endoscopic findings in Japan, where the H. pylori infection rate is higher than in Western populations, has not been fully elucidated. ${ }^{(17,18)}$

Because some endoscopic findings may be related to functional gastrointestinal abnormalities and/or dyspeptic symptoms, ${ }^{(17,18)}$ identifying the characteristic findings may help clarify the pathophysiology of an individual's dyspeptic symptoms and the development of endoscopic findings. Thus, we retrospectively investigated how endoscopic findings and severity of gastritis are related to $H$. pylori in patients with and without dyspeptic symptoms.

\section{Materials and Methods}

Patients and study protocol. The study protocol conforms to the ethical guidelines of the Declaration of Helsinki, ${ }^{(19)}$ The protocol of this study was reviewed and approved by the Institu-

*To whom correspondence should be addressed.

E-mail: t-kawai@tokyo-med.ac.jp 
Table 1. Definition of $H$. pylori infection status

\begin{tabular}{|c|c|c|c|c|c|}
\hline $\begin{array}{l}\text { H. pylori } \\
\text { lgG }\end{array}$ & Atrophy & $\begin{array}{l}\text { Diffuse } \\
\text { redness }\end{array}$ & $\begin{array}{l}\text { H. pylori } \\
\text { infection }\end{array}$ & $\begin{array}{c}\text { Past } \\
\text { H. pylori }\end{array}$ & $\begin{array}{l}\text { H. pylori } \\
\text { negative }\end{array}$ \\
\hline$\geq 10$ & & & ० & & \\
\hline \multirow[t]{3}{*}{$\geq 3,<10$} & + & + & o & & \\
\hline & + & - & & o & \\
\hline & - & - & & & o \\
\hline \multirow[t]{2}{*}{$<3$} & + & - & & ○ & \\
\hline & - & - & & & 0 \\
\hline
\end{tabular}

tional Review Board of Tokyo Medical University. This study enrolled subjects who underwent endoscopy as part of a health check-up or secondary check-up for gastric cancer after a barium X-ray examination from August 2003 to April 2004 at Fuyo Clinic, Tokyo. Inclusion criteria were subjects who underwent endoscopy at Fuyo Clinic and completed a score sheet on dyspeptic symptoms. Exclusion criteria were a history of esophageal and gastric surgery, lack of data on subject's background and lack of clear endoscopic images to evaluate endoscopic findings. Because this study was a retrospective observational study and written informed consent was not obtained from each patient, a document declaring an opt-out policy, through which any patient could refuse to be included in this study, was uploaded on the websites of Fuyo Clinic and Tokyo Medical University Hospital.

In this study, $H$. pylori infection was diagnosed using an anti-H. pylori IgG test and endoscopic findings of atrophy and diffuse redness (Table 1). The presence or absence of abdominal symptoms, such as heartburn, abdominal pain, nausea, distention, epigastric discomfort, and epigastralgia, were determined using a questionnaire. Patients with dyspepsia were defined as those with abdominal symptoms of heartburn, distention, nausea, epigastric discomfort, epigastralgia or abdominal pain. All patients underwent gastroduodenal endoscopy to determine endoscopic findings and severity of gastritis.

Endoscopy and severity of gastritis. Gastroduodenal endoscopy was performed and the severity of gastritis was scored according to the Kyoto gastritis classification and the KimuraTakemoto classification. ${ }^{(20,21)}$ In the Kyoto classification, the total score includes five parameters of gastritis, namely, atrophy (Kimura-Takemoto classification $\mathrm{CI}=$ Kyoto $\mathrm{A} 0, \mathrm{CII}-\mathrm{CIII}=$ Kyoto A1, and $\mathrm{OI}-\mathrm{OIII}=$ Kyoto A2), intestinal metaplasia (None: IM0, within antrum: IM1 and up to corpus: IM2), hypertrophy of gastric folds (negative: H0, positive: H1), nodularity (negative: N0, positive: N1), and diffuse redness (negative: DR0, mild: DR1, severe: DR2) ${ }^{(5-8)}$ The presence of gastroesophageal reflux disease (GERD) was assessed according to the Los Angeles classification. ${ }^{(22)}$

Data analysis. Age, body mass index (BMI) and Kyoto classification scores are presented as mean \pm SD. Statistically significant differences in category among any groups were determined using the $\chi^{2}$ test. Statistically significant differences in endoscopic score between two groups (dyspepsia-positive vs -negative) were determined using the Mann-Whitney $U$ test, and those among three groups ( $H$. pylori-positive, -negative, and eradicated) were determined using the Mann-Whitney $U$ test after significant differences were observed in the Kruskal-Wallis test. Statistically significant differences in mean age and BMI values between two groups (dyspepsia-positive vs negative) were determined using Student's $t$ test, and those among three groups (H. pylori-positive, -negative, and eradicated) were determined using one-way ANOVA followed by the Scheffé multiple comparisons test. Univariate and multivariate logistic regression analyses were used to test the associations of candidate variables with development of dyspeptic symptoms. Multicollinearity among the variables was tested using the variance inflation factor. Factors with a $p$ value $<0.2$ in the univariate analysis were further examined using multivariate analysis for their association with the risk of developing abdominal symptoms. $P<0.05$ was considered statistically significant and all $p$ values were twosided. Analyses were conducted using SPSS ver. 27 (IBM Inc.; Armonk, NY).

\section{Results}

Patient characteristics in relation to $\boldsymbol{H}$. pylori infection status. This study enrolled 418 subjects who underwent endoscopy as part of a health check-up from August 2003 to April 2004 at Fuyo Clinic, Tokyo. Of the 418 subjects, 34.7\% $(145 / 418)$ and $50.2 \%(210 / 418)$ were $H$. pylori-positive and -negative, respectively (Table 2).

When the patients were divided into three groups $[H$. pylorinegative $(n=210)$, -positive $(n=145)$, and previously infected $(n=63)], H$. pylori-positive patients were older and had higher incidence of hypertension than those in the other groups (Table 2). Other characteristics, such as alcohol consumption, smoking status, disease incidence and drugs, were similar among the three groups. H. pylori-positive patients also had higher incidence of endoscopic findings of gastric ulcer, duodenal ulcer, duodenal ulcer scar, Kyoto gastritis classification score, xanthoma, hyperplastic polyp, mucosal swelling, sticky mucous, spotty redness, and multiple white and flat elevated lesions than those in the other groups (Table 3). In contrast, H. pylori-negative patients had higher incidence of short-segment Barrett's esophagus (SSBE), GERD, hiatal hernia, regular arrangement of collecting venules, hematin, red streak, and fundic gland polyp than those in the other groups (Table 3 ). There was no significant difference in the incidence of abdominal symptoms among the three groups (Table 4).

Patient characteristics in relation to dyspeptic symptoms. Patients with dyspepsia were defined as patients with symptoms such as heartburn, distention, nausea, epigastric discomfort, epigastralgia or abdominal pain. Of the 418 patients, $21.3 \%$ $(89 / 418)$ reported symptoms in the questionnaire (Table 2). Patients with dyspeptic symptoms were more likely to be female $(p=0.014)$ and taking HMG-CoA reductase inhibitor $(p=0.006)$ or antianxiety drugs $(p=0.001)$. The other characteristics were similar between patients with and without dyspeptic symptoms (Table 2).

While most endoscopic findings were similar between patients with and without dyspepsia, the prevalence of SSBE and fundic gland polyp was significantly different $(p=0.034$ and 0.004 , respectively) (Table 3 ). The Kyoto classification score for enlarged folds was higher in patients with dyspepsia, while scores for atrophy, intestinal metaplasia, nodularity, and diffuse redness were similar between the two groups (Table 3 ).

Dyspepsia patients had higher incidence of a feeling of incomplete defecation and lower abdominal pain than patients without symptoms ( $p=0.004$ and $p<0.001$, respectively) (Table 4).

Risk factors for the incidence of dyspeptic symptoms. In univariate analysis, fundic gland polyp [odds ratio (OR): 3.173, 95\% CI: $1.387-7.260, p=0.006]$ was identified as a risk factor for dyspeptic symptoms, and sex (male) (OR: $0.317,95 \% \mathrm{CI}$ : $0.121-0.830, p=0.014$ ) and SSBE (OR: $0.602,95 \%$ CI: $0.376-$ $0.964, p=0.034$ ) as preventive factors (Table 5). Factors with a $p$ value $<0.2$ in the univariate analysis (age, sex, SSBE, gastric ulcer scar, atrophy, fundic gland polyp, and sticky mucous) were subjected to multivariate analysis. Ultimately, fundic gland polyp was identified as a risk factor for dyspeptic symptoms (OR: 3.414, 95\% CI: 1.430-8.142), and short-segment Barrett's esophagus and male sex as protective factors (OR: 0.569, 95\% 
Table 2. Characteristics of patients enrolled in this study

\begin{tabular}{|c|c|c|c|c|c|c|c|c|}
\hline & $\begin{array}{l}\text { All patients } \\
(n=418)\end{array}$ & $\begin{array}{l}\text { H. pylori } \\
\text { infection } \\
(n=145)\end{array}$ & $\begin{array}{c}\text { Past } H . \text { pylori } \\
\text { infection } \\
(n=63)\end{array}$ & $\begin{array}{l}\text { H. pylori } \\
\text { negative } \\
(n=210)\end{array}$ & $p$ value & $\begin{array}{l}\text { Dyspepsia } \\
\text { positive } \\
(n=89)\end{array}$ & $\begin{array}{l}\text { Dyspepsia } \\
\text { negative } \\
(n=329)\end{array}$ & $p$ value \\
\hline Age (years) & $39.2 \pm 8.3$ & $42.6 \pm 8.7$ & $37.8 \pm 7.9$ & $37.2 \pm 7.5$ & $<0.001$ & $38.0 \pm 8.2$ & $39.5 \pm 8.4$ & 0.145 \\
\hline Sex (male, $n, \%)$ & $400(95.7 \%)$ & $139(96.5 \%)$ & $61(96.8 \%)$ & $200(95.2 \%)$ & 0.856 & $81(91.0 \%)$ & $319(97.0 \%)$ & 0.014 \\
\hline Body mass index $\left(\mathrm{kg} / \mathrm{m}^{2}\right)$ & $23.5 \pm 3.6$ & $23.9 \pm 3.6$ & $23.1 \pm 3.1$ & $23.3 \pm 3.2$ & 0.194 & $23.8 \pm 3.3$ & $23.4 \pm 3.4$ & 0.848 \\
\hline Smoking $(n, \%)$ & $176(46.0 \%)$ & $66(50.4 \%)$ & $24(41.4 \%)$ & $86(44.3 \%)$ & 0.421 & $43(48.9 \%)$ & $133(45.1 \%)$ & 0.532 \\
\hline Alcohol consumption $(n, \%)$ & $243(63.4 \%)$ & $87(66.4 \%)$ & $37(63.8 \%)$ & $119(61.3 \%)$ & 0.647 & $58(65.9 \%)$ & $185(62.7 \%)$ & 0.585 \\
\hline Helicobacter pylori infection ( $n, \%)$ & $144(34.4 \%)$ & $145(100 \%)$ & $0(0 \%)$ & $0(0.0 \%)$ & $<0.001$ & $47(52.8 \%)$ & $149(45.3 \%)$ & 0.207 \\
\hline \multicolumn{9}{|l|}{ Disease } \\
\hline Hypertension $(n, \%)$ & $37(8.9 \%)$ & $20(13.9 \%)$ & $3(5.0 \%)$ & $14(6.5 \%)$ & 0.031 & $6(6.7 \%)$ & $31(9.4 \%)$ & 0.43 \\
\hline Hyperlipidemia $(n, \%)$ & $5(1.2 \%)$ & $1(0.7 \%)$ & $2(3.3 \%)$ & $2(0.9 \%)$ & 0.286 & $2(2.2 \%)$ & $3(0.9 \%)$ & 0.304 \\
\hline Diabetes mellitus ( $n, \%)$ & $5(1.2 \%)$ & $2(1.4 \%)$ & $0(0.0 \%)$ & $3(1.4 \%)$ & 0.638 & $1(1.1 \%)$ & $4(1.2 \%)$ & 0.943 \\
\hline Heart diseases $(n, \%)$ & $11(2.6 \%)$ & $5(3.5 \%)$ & $2(3.3 \%)$ & $4(1.9 \%)$ & 0.643 & $3(3.4 \%)$ & $8(2.4 \%)$ & 0.623 \\
\hline Cancer $(n, \%)$ & $2(0.5 \%)$ & $1(0.7 \%)$ & $0(0.0 \%)$ & $1(0.5 \%)$ & 0.803 & $0(0.0 \%)$ & $2(0.6 \%)$ & 0.461 \\
\hline \multicolumn{9}{|l|}{ Drugs } \\
\hline Antihypertensive drug $(n, \%)$ & $3(0.7 \%)$ & $2(1.4 \%)$ & $1(1.7 \%)$ & $0(0.0 \%)$ & 0.215 & $1(1.1 \%)$ & $2(0.6 \%)$ & 0.609 \\
\hline $\begin{array}{l}\text { 3-hydroxy-3-methylglutaryl-CoA reductase } \\
\text { inhibitor }(n, \%)\end{array}$ & $2(0.5 \%)$ & $0(0.0 \%)$ & $1(1.7 \%)$ & $1(0.5 \%)$ & 0.313 & $2(2.2 \%)$ & $0(0.0 \%)$ & 0.006 \\
\hline Hypoglycemic drug $(n, \%)$ & $1(0.2 \%)$ & $1(0.7 \%)$ & $0(0.0 \%)$ & $0(0.0 \%)$ & 0.389 & $0(0.0 \%)$ & $1(0.3 \%)$ & 0.603 \\
\hline Antianxiety drugs ( $n, \%)$ & $3(0.7 \%)$ & $0(0.0 \%)$ & $0(0.0 \%)$ & $3(1.4 \%)$ & 0.224 & $3(3.4 \%)$ & $0(0.0 \%)$ & 0.001 \\
\hline Non-steroidal anti-inflammatory drugs $(n, \%)$ & $2(0.5 \%)$ & $0(0.0 \%)$ & $0(0.0 \%)$ & $2(0.9 \%)$ & 0.37 & $0(0.0 \%)$ & $2(0.6 \%)$ & 0.461 \\
\hline Histamine receptor antagonist $(n, \%)$ & $1(0.2 \%)$ & $1(0.7 \%)$ & $0(0.0 \%)$ & $0(0.0 \%)$ & 0.389 & $0(0.0 \%)$ & $1(0.3 \%)$ & 0.603 \\
\hline Nitrate $(n, \%)$ & $1(0.2 \%)$ & $0(0.0 \%)$ & $0(0.0 \%)$ & $1(0.5 \%)$ & 0.609 & $0(0.0 \%)$ & $1(0.3 \%)$ & 0.603 \\
\hline
\end{tabular}

CI: $0.349-0.928$ and OR: $0.333,95 \%$ CI: $0.117-0.948$, respectively) (Table 5).

\section{Discussion}

The incidence of fundic gland polyp was higher among health check-up subjects with dyspeptic symptoms than those without, irrespective of endoscopic severity of gastritis and other endoscopic findings. In addition, fundic gland polyp was significantly associated with dyspeptic symptoms. Evidence suggests that fundic gland polyps are typically found in $H$. pylori-negative patients. ${ }^{(23)}$ Given that the H. pylori infection rate is decreasing to $30 \%$ in Japan and the proportion of patients with dyspeptic symptoms is expected to increase, fundic gland polyps may be a useful indicator for identifying present and future patients with dyspeptic symptoms.

Endoscopic findings and dyspeptic symptoms. The Kyoto Classification of Gastritis was proposed at the 85th Congress of the Japan Gastroenterological Endoscopy Society in 2014 as a tool for standardizing endoscopic findings. Although endoscopic findings and abdominal symptoms are useful indicators of a patient's ability to secrete gastric acid, $H$. pylori infection status and lifestyle (i.e., food, smoking, and medication), that H. pylori infection affects gastric condition and the development of gastric diseases means that it is important to clarify whether patients are infected with H. pylori. ${ }^{(24)}$ However, the association of H. pylori infection with FD or dyspeptic symptoms; endoscopic findings such as endoscopic gastritis, peptic ulcer, gastric cancer, atrophy and erosion; and severity of gastritis has not been well investigated. ${ }^{(18,24-30)}$ Jung et al. ${ }^{(26)}$ reported that although about $40 \%$ of Korean patients with dyspeptic symptoms had endoscopic findings (i.e., peptic ulcer, reflux esophagitis, Barrett's esophagus, erosions, and gastric cancer), no particular finding was characteristic of patients with dyspeptic symptoms. However, Tahara et al. ${ }^{(18)}$ reported that red streak in the antrum and duodenal ulcer scar in 87 Japanese patients with dyspeptic symptoms were independently associated with dyspepsia (OR: 3.90,
95\% CI: $1.20-12.64$ and OR: $3.41,95 \%$ CI: $1.08-10.79$, respectively). In addition, in univariate analysis of the risk factors of dyspepsia on endoscopic findings, Tanaka et al. ${ }^{(17)}$ showed that a significantly lower proportion of FD patients had red streak compared to healthy non-symptomatic controls $(0 \%$ vs $18.6 \%$; $p=0.0124$ ). Further, FD patients were more likely to have depressive erosion $(20.0 \%$ vs $7.9 \% ; p=0.0522)$. However, these studies reported no significant differences in other endoscopic findings ${ }^{(18,25)}$ or histological findings for inflammation and atrophy. ${ }^{(18)}$ In this study, we found that although most endoscopic findings, severity of gastritis according to the Kyoto gastritis classification, and $H$. pylori infection status were not significantly correlated with dyspeptic symptoms, an endoscopic finding of fundic gland polyp may be associated with dyspeptic symptoms. The discrepancy between our findings and those of previous reports may be explained by the fact that the patients enrolled in this study were young and underwent endoscopy as part of a health check-up, and that not all patients with dyspeptic symptoms had FD.

Fundic gland polyp and dyspeptic symptoms. Fundic gland polyp is the most common type of gastric polyp detected using endoscopy. It is found in approximately $6 \%$ of patients who undergo endoscopy and represents $74 \%$ of all gastric polyps identified on histological evaluation. ${ }^{(30)}$ A Chinese study showed that although the prevalence of endoscopic gastric polyps was similar between 2000 and 2010 [1.0\% $(68 / 6,784)$ vs $1.1 \%$ $(183 / 17,337)]$, that of fundic gland polyps increased from $8.8 \%$ to $66.1 \%{ }^{\left({ }^{(32)}\right.}$ This change in the prevalence of gastric polyps over the past $10-20$ years is most likely due to a decrease in the H. pylori infection rate.

Although the present study failed to show a significant association between dyspeptic symptoms and red streak in the antrum or depressive erosion, like fundic gland polyp, red streak and depressive erosion are characteristic of $H$ pylori infectionnegative patients. Gastric acid secretion is typically significantly different between $H$ pylori-positive and -negative patients, with $H$ pylori-positive patients showing decreased gastric acid secre- 
Table 3. Endoscopic characteristics of patients enrolled in this study

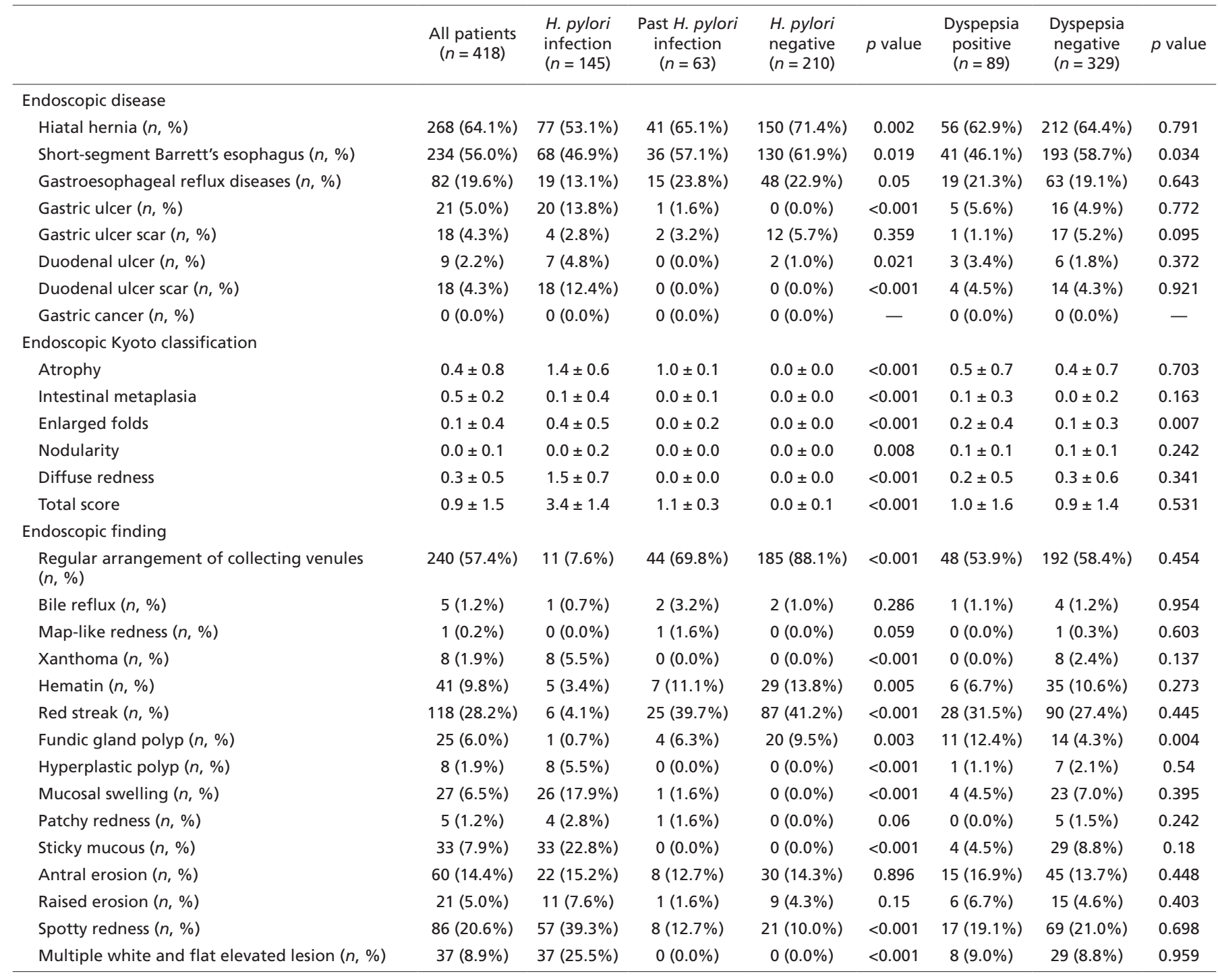

Table 4. Abdominal symptoms of patients enrolled in this study

\begin{tabular}{|c|c|c|c|c|c|c|c|c|}
\hline & $\begin{array}{l}\text { All patients } \\
\quad(n=418)\end{array}$ & $\begin{array}{l}\text { H. pylori } \\
\text { infection } \\
(n=145)\end{array}$ & $\begin{array}{c}\text { Past } H \text {. pylori } \\
\text { infection } \\
(n=63)\end{array}$ & $\begin{array}{l}H . \text { pylori } \\
\text { negative } \\
(n=210)\end{array}$ & $p$ value & $\begin{array}{l}\text { Dyspepsia } \\
\text { positive } \\
(n=89)\end{array}$ & $\begin{array}{l}\text { Dyspepsia } \\
\text { negative } \\
(n=329)\end{array}$ & $p$ value \\
\hline Heart burn $(n, \%)$ & $31(7.4 \%)$ & $13(9.0 \%)$ & $5(7.9 \%)$ & $13(6.2 \%)$ & 0.609 & $31(34.8 \%)$ & $0(0.0 \%)$ & $<0.001$ \\
\hline Nausea $(n, \%)$ & $11(2.6 \%)$ & $3(2.1 \%)$ & $2(3.2 \%)$ & $6(2.9 \%)$ & 0.864 & $11(12.4 \%)$ & $0(0.0 \%)$ & $<0.001$ \\
\hline Epigastric discomfort, before meal $(n, \%)$ & $2(0.5 \%)$ & $0(0.0 \%)$ & $0(0.0 \%)$ & $2(1.0 \%)$ & 0.37 & $2(2.2 \%)$ & $0(0.0 \%)$ & 0.006 \\
\hline Epigastralgia, before meal $(n, \%)$ & $15(3.6 \%)$ & $7(4.8 \%)$ & $2(3.2 \%)$ & $6(2.9 \%)$ & 0.607 & $15(16.9 \%)$ & $0(0.0 \%)$ & $<0.001$ \\
\hline Dysphagia $(n, \%)$ & $10(2.4 \%)$ & $1(0.7 \%)$ & $1(1.6 \%)$ & $8(3.8 \%)$ & 0.151 & $10(11.2 \%)$ & $0(0.0 \%)$ & $<0.001$ \\
\hline Abdominal pain $(n, \%)$ & $25(6.0 \%)$ & $9(6.2 \%)$ & $2(3.2 \%)$ & $14(6.7 \%)$ & 0.585 & $25(28.1 \%)$ & $0(0.0 \%)$ & $<0.001$ \\
\hline Appetite loss ( $n, \%)$ & $7(1.7 \%)$ & $1(0.7 \%)$ & $2(3.2 \%)$ & $4(1.9 \%)$ & 0.41 & $76(6.7 \%)$ & $1(0.3 \%)$ & $<0.001$ \\
\hline Defecation disorder $(n, \%)$ & $36(8.6 \%)$ & $13(9.0 \%)$ & $7(11.1 \%)$ & $16(7.6 \%)$ & 0.675 & $10(11 / 2 \%)$ & $26(7.9 \%)$ & 0.32 \\
\hline
\end{tabular}


Table 5. Univariate and multivariate analysis of the development of dyspepsia

\begin{tabular}{|c|c|c|c|c|c|c|}
\hline \multirow[b]{2}{*}{ Parameter } & \multicolumn{3}{|c|}{ Univariate analysis } & \multicolumn{3}{|c|}{ Multivariate analysis } \\
\hline & Odds ratio & $95 \% \mathrm{Cl}$ & $p$ value & Odds ratio & $95 \% \mathrm{Cl}$ & $p$ value \\
\hline Age & 0.979 & $0.952-1.007$ & 0.145 & & & \\
\hline Body mass index $>22\left(\mathrm{~kg} / \mathrm{m}^{2}\right)$ & 0.898 & $0.527-1.528$ & 0.691 & & & \\
\hline Smoking & 1.164 & $0.723-1.875$ & 0.532 & & & \\
\hline Alcohol consumption & 1.15 & $0.697-1.895$ & 0.585 & & & \\
\hline \multicolumn{7}{|l|}{ Disease } \\
\hline Hypertension & 0.695 & $0.280-1.722$ & 0.43 & & & \\
\hline Hyperlipidemia & 2.498 & $0.411-15.185$ & 0.304 & & & \\
\hline Diabetes mellitus & 0.923 & $0.102-8.366$ & 0.943 & & & \\
\hline Heart diseases & 1.4 & $0.364-5.389$ & 0.623 & & & \\
\hline Cancer & 0.944 & $0.986-1.002$ & 0.461 & & & \\
\hline Gastroesophageal reflux diseases & 1.146 & $0.644-2.040$ & 0.643 & & & \\
\hline Gastric ulcer & 1.161 & $0.415-2.270$ & 0.773 & & & \\
\hline Gastric ulcer scar & 0.209 & $0.027-1.589$ & 0.13 & 0.119 & $0.014-1.036$ & 0.054 \\
\hline Duodenal ulcer & 1.238 & $0.245-6.239$ & 0.796 & & & \\
\hline Duodenal ulcer scar & 1.243 & $0.391-3.952$ & 0.721 & & & \\
\hline \multicolumn{7}{|l|}{ Endoscopic Kyoto classification } \\
\hline Atrophy & 0.782 & $0.556-1.098$ & 0.155 & 0.868 & $0.568-1.326$ & 0.513 \\
\hline Intestinal metaplasia & 0.616 & $0.192-1.975$ & 0.415 & & & \\
\hline Enlarged folds & 0.87 & $0.441-1.714$ & 0.687 & & & \\
\hline Nodularity & 0.4 & $0.066-2.433$ & 0.32 & & & \\
\hline Diffuse redness & 0.268 & $0.513-1.331$ & 0.433 & & & \\
\hline Red streak & 1.264 & $0.763-2.094$ & 0.362 & & & \\
\hline Fundic gland polyp & 3.173 & $1.387-7.260$ & 0.006 & 3.413 & $1.430-8.142$ & 0.006 \\
\hline Hyperplastic polyp & 0.523 & $0.063-4.305$ & 0.54 & & & \\
\hline Mucosal swelling & 0.626 & $0.211-1.860$ & 0.395 & & & \\
\hline Patchy redness & 0.985 & $0.972-0.998$ & 0.242 & & & \\
\hline Sticky mucous & 0.487 & $0.167-1.423$ & 0.18 & 0.199 & $0.203-2.408$ & 0.571 \\
\hline Antral erosion & 1.279 & $0.676-2.421$ & 0.448 & & & \\
\hline Raised erosion & 1.513 & $0.570-4.021$ & 0.403 & & & \\
\hline Spotty redness & 0.89 & $0.492-1.607$ & 0.698 & & & \\
\hline Multiple white and flat elevated lesion & 1.022 & $0.450-2.320$ & 0.959 & & & \\
\hline
\end{tabular}

tion due to the progression of gastric atrophy and upregulation of activated pro-inflammatory cytokines. ${ }^{(33)}$ Therefore, greater gastric acid secretion in $H$ pylori-negative patients may increase the risk of dyspeptic symptoms. A meta-analysis of randomized controlled trials comparing any proton pump inhibitor (PPI) with placebo or prokinetics for the treatment of FD showed that PPIs were more effective than placebo (RR: $0.88,95 \%$ CI: $0.82-0.94$ ) and slightly more effective than prokinetics (RR: $0.89,95 \% \mathrm{CI}$ : 0.81-0.99) at relieving overall dyspeptic symptoms in FD patients. ${ }^{(34)}$ This evidence suggests that PPIs are effective treatments for FD, in whom dyspeptic symptoms may be related to gastric acidity. However, it remains unclear whether fundic gland polyps are responsible for dyspeptic symptoms; thus, further study is required to clarify the direct association among gastric acidity, fundic gland polyps and dyspeptic symptoms.

Limitations. This study has a few limitations. First, this was a single-center retrospective study with a small sample size. Second, we did not have data on the severity of dyspeptic symptoms and did not use established questionnaires such as the $\mathrm{F}$ scale $^{(35,36)}$ and the gastrointestinal symptom rating scale. ${ }^{(36,37)}$ Third, although $H$. pylori infection was diagnosed using an anti$H$ pylori IgG test and endoscopic findings of atrophy and diffuse 
redness, $H$. pylori infection status $(H$. pylori-positive, -negative, and eradicated) is difficult to confirm with confidence. Fourth, because we did not have data on the duration of abdominal symptoms, we were unable to diagnose functional dyspepsia in patients with dyspeptic symptoms.

\section{Conclusion}

The presence of fundic gland polyps is a risk factor for dyspeptic symptoms in Japanese subjects who underwent endoscopy as part of a health check-up. Although details of the mechanism underlying the development of dyspepsia in patients with fundic gland polyps are unclear, that fundic gland polyp is a characteristic endoscopic finding in $H$. pylori-negative subjects suggests that it may be related to $H$. pylori infection or gastric acid secretion.

\section{Author Contributions}

Conceptualization, KT, MS, and TK; methodology, KT, MS, and TK; software, KT and MS; formal analysis, KT and MS;

\section{References}

1 Parsonnet J, Friedman GD, Vandersteen DP, et al. Helicobacter pylori infection and the risk of gastric carcinoma. N Engl J Med 1991; 325: 1127-1131.

2 Infection with Helicobacter pylori. IARC Monogr Eval Carcinog Risks Hum 1994; 61: 177-241.

3 Tsuda M, Asaka M, Kato M, et al. Effect on Helicobacter pylori eradication therapy against gastric cancer in Japan. Helicobacter 2017; 22: e12415.

4 Graham DY. Helicobacter pylori infection in the pathogenesis of duodenal ulcer and gastric cancer: a model. Gastroenterology 1997; 113: 1983-1991.

5 Sugimoto M, Ban H, Ichikawa H, et al. Efficacy of the Kyoto classification of gastritis in identifying patients at high risk for gastric cancer. Intern Med 2017; 56: 579-586.

6 Dixon MF, Genta RM, Yardley JH, Correa P. Classification and grading of gastritis. The updated Sydney System. International Workshop on the Histopathology of Gastritis, Houston 1994. Am J Surg Pathol 1996; 20: 1161-1181.

7 Rugge M, Correa P, Di Mario F, et al. OLGA staging for gastritis: a tutorial. Dig Liver Dis 2008; 40: 650-658.

8 Rugge M, Meggio A, Pennelli G, et al. Gastritis staging in clinical practice: the OLGA staging system. Gut 2007; 56: 631-636.

9 Shichijo S, Hirata Y, Niikura R, Hayakawa Y, Yamada A, Koike K. Association between gastric cancer and the Kyoto classification of gastritis. $J$ Gastroenterol Hepatol 2017; 32: 1581-1586.

10 Dohi O, Majima A, Naito Y, et al. Can image-enhanced endoscopy improve the diagnosis of Kyoto classification of gastritis in the clinical setting? Dig Endosc 2020; 32: 191-203.

11 Otani K, Watanabe T, Kosaka S, et al. Utility of Kyoto Classification of Gastritis in subjects with a high-negative titer of anti-Helicobacter pylori antibody during a medical check-up. J Clin Biochem Nutr 2020; 67: 317-322.

12 Aziz I, Palsson OS, Törnblom H, Sperber AD, Whitehead WE, Simrén M. Epidemiology, clinical characteristics, and associations for symptom-based Rome IV functional dyspepsia in adults in the USA, Canada, and the UK: a cross-sectional population-based study. Lancet Gastroenterol Hepatol 2018; 3: $252-262$.

13 Tominaga K, Fujikawa Y, Tsumoto C, et al. Disorder of autonomic nervous system and its vulnerability to external stimulation in functional dyspepsia. $J$ Clin Biochem Nutr 2016; 58: 161-165

14 Tominaga K, Arakawa T. Kampo medicines for gastrointestinal tract disorders: a review of basic science and clinical evidence and their future application. $J$ Gastroenterol 2013; 48: 452-462.

15 Moayyedi P, Lacy BE, Andrews CN, Enns RA, Howden CW, Vakil N. ACG and CAG Clinical Guideline: Management of Dyspepsia. Am J Gastroenterol 2017; 112: 988-1013.

16 Miwa H, Kusano M, Arisawa T, et al. Evidence-based clinical practice guidelines for functional dyspepsia. J Gastroenterol 2015; 50: 125-139. investigation, TO and TK; writing-original draft preparation, KT, MS, and TK; writing-review and editing, KT, MS, MH, NN, EI, RN, MF, TI, TO, TK; supervision, TO, TI, TK; project administration, TO and TK.

\section{Acknowledgments}

We thank Heidi Tran, PhD, and Guy Harris, DO, from DMC Corp. (www.dmed.co.jp) for editing drafts of this manuscript.

\section{Abbreviations}

GERD gastroesophageal reflux disease

H. pylori Helicobacter pylori

OR odds ratio

SSBE short-segment Barrett's esophagus

\section{Conflict of Interest}

No potential conflicts of interest were disclosed.

17 Tanaka F, Tominaga K, Fujikawa Y, et al. Association between functional dyspepsia and gastric depressive erosions in Japanese subjects. Intern Med 2019; 58: 321-328.

18 Tahara T, Arisawa T, Shibata T, et al. Association of endoscopic appearances with dyspeptic symptoms. J Gastroenterol 2008; 43: 208-215.

19 World Medical Association. World Medical Association Declaration of Helsinki: ethical principles for medical research involving human subjects. JAMA 2013; 310: 2191-2194.

20 Kamada T, Haruma K, Inoue K, Shiotani A. Helicobacter pylori infection and endoscopic gastritis-Kyoto classification of gastritis. Nihon Shokakibyo Gakkai Zasshi 2015; 112: 982-993. (in Japanese)

21 Kimura K, Takemoto T. An endoscopic recognition of the atrophic border and its significance in chronic gastritis. Endoscopy 1969; 1: 87-97.

22 Armstrong D, Bennett JR, Blum AL, et al. The endoscopic assessment of esophagitis: a progress report on observer agreement. Gastroenterology 1996; 111: 85-92

23 Malfertheiner P, Kandulski A, Venerito M. Proton-pump inhibitors: understanding the complications and risks. Nat Rev Gastroenterol Hepatol 2017; 14: $697-710$.

24 Hatta W, Iijima K, Koike T, et al. Endoscopic findings for predicting gastric acid secretion status. Dig Endosc 2015; 27: 582-589.

25 Tanaka M, Ono H, Hasuike N, Takizawa K. Endoscopic submucosal dissection of early gastric cancer. Digestion 2008; 77 Suppl 1: 23-28.

26 Jung HK, Kim SE, Shim KN, Jung SA. Association between dyspepsia and upper endoscopic findings. Korean J Gastroenterol 2012; 59: 275-281. (in Korean)

27 Vaira D, Holton J, Osborn J, et al. Endoscopy in dyspeptic patients: is gastric mucosal biopsy useful? Am J Gastroenterol 1990; 85: 701-704.

28 Perri F, Clemente R, Festa V, et al. Patterns of symptoms in functional dyspepsia: role of Helicobacter pylori infection and delayed gastric emptying. Am J Gastroenterol 1998; 93: 2082-2088.

29 Lu CL, Chang FY, Chen TS, Chen CY, Jiun KL, Lee SD. Helicobacter pylori colonization does not influence the symptomatic response to prokinetic agents in patients with functional dyspepsia. J Gastroenterol Hepatol 1998; 13: 500 504.

30 Schubert TT, Schubert AB, Ma CK. Symptoms, gastritis, and Helicobacter pylori in patients referred for endoscopy. Gastrointest Endosc 1992; 38: $357-$ 360.

31 Carmack SW, Genta RM, Schuler CM, Saboorian MH. The current spectrum of gastric polyps: a 1-year national study of over 120,000 patients. Am J Gastroenterol 2009; 104: 1524-1532.

32 Cao H, Wang B, Zhang Z, Zhang H, Qu R. Distribution trends of gastric polyps: an endoscopy database analysis of 24121 northern Chinese patients. $J$ Gastroenterol Hepatol 2012; 27: 1175-1180. 
33 Kinoshita Y, Kawanami C, Kishi K, Nakata H, Seino Y, Chiba T. Helicobacter pylori independent chronological change in gastric acid secretion in the Japanese. Gut 1997; 41: 452-458.

34 Pinto-Sanchez MI, Yuan Y, Hassan A, Bercik P, Moayyedi P. Proton pump inhibitors for functional dyspepsia. Cochrane Database Syst Rev 2017; 11: CD011194.

35 Kusano M, Shirai N, Yamaguchi K, et al. It is possible to classify non-erosive reflux disease (NERD) patients into endoscopically normal groups and minimal change groups by subjective symptoms and responsiveness to rabeprazole — a report from a study with Japanese patients. Dig Dis Sci 2008; 53: 3082-3094.
36 Sugimoto $\mathrm{M}$, Hasegawa $\mathrm{T}$, Nishino $\mathrm{M}$, et al. Improvement of gastroesophageal reflux disease in Japanese patients with spinal kyphotic deformity who underwent surgical spinal correction. Dig Endosc 2016; 28: 50-58.

37 Svedlund J, Sjödin I, Dotevall G. GSRS - a clinical rating scale for gastrointestinal symptoms in patients with irritable bowel syndrome and peptic ulcer disease. Dig Dis Sci 1988; 33: 129-134.

(C) This is an open access article distributed under the terms of the cc) $-($ Creative Commons Attribution-NonCommercial-NoDerivatives BY NC ND License (http://creativecommons.org/licenses/by-nc-nd/4.0/). 